\title{
Inferring the Personalities of B2B Salespeople from Text-Based Interviews: An Exploratory Study: An Abstract
}

\author{
Christine Pitt, Neil Lilford, and Albert Caruana
}

\begin{abstract}
Identifying the traits of the successful salesperson has long been a challenge to both sales practitioners and marketing scholars. The costs of poor recruiting, selection, and hiring decisions are considerable, and so ideally, firms would like to be able to identify as quickly and as effectively as possible what makes a highperforming salesperson. This is especially true in B2B environments, where personal selling is still a very important part of a firm's marketing communication mix. A number of tools, including personality analysis, have been used over the years to attempt to identify the traits of the successful sales performer. This paper describes a study in which the text from depth interviews with a sample of salespersons in a B2B environment was subjected to content analysis using IBM's Watson software to produce personality profiles of the individual salespersons. The salespersons could then be segmented into different groups, depending on their personality traits. The limitations are acknowledged, managerial implications discussed, and avenues for future research identified.
\end{abstract}

References Available Upon Request

\section{Pitt $(\bowtie) \cdot$ N. Lilford}

Royal Institute of Technology (KTH), Stockholm, Sweden

e-mail: christinepitt91@gmail.com; neil@greenfieldsbus.com

\author{
A. Caruana \\ University of Malta, Msida, Malta \\ e-mail: albert.caruana@um.edu.mt
}

